\title{
INVENTORY PROJECT FOR THE CULTURAL ASSETS OF ISTANBUL: A MODEL FOR DIGITIZATION OF CULTURAL HERITAGE
}

\author{
E. Kudde ${ }^{1 *}$, I. Erdogan ${ }^{1}$, I. Ilze ${ }^{1}$ \\ ${ }^{1}$ ISTANBUL METROPOLITAN MUNICIPALITY, Directorate of Cultural Heritage Preservation, 34134 Fatih ISTANBUL, Turkey \\ - (esra.kudde, islam.erdogan, iilze)@ibb.gov.tr
}

Commission VI, WG VI/4

KEY WORDS: Inventory, Data acquisition, Data processing, Management, Cultural heritage

\begin{abstract}
:
Directorate of Cultural Heritage Preservation of Istanbul Metropolitan Municipality had started an Inventory Project in 2015, for gathering the varying information of historical and cultural assets. Although there had been previous studies conducted by various institutions or local establishments, the absence of accessibility to whole updated database of historical values was a matter of concern, both for government and research studies. For this reason, it was aimed to create and update Istanbul Historical Database. The Directorate assumed the responsibility of creating the database and providing its accessibility through web and publications. It was also aimed to provide accurate information and multimedia, not only for existing but also further projects in respect of cultural heritage and preservation. There have been 41 people from different professions such as architects, restorers, urban planners, archaeologists and art historians being employed in this work. A huge amount of data including old maps, photographs, documents, drawings and projects were brought together and classified according to their contents. Afterwards, all registered values including monuments, civil architectural or urban elements were visited, observed and photographed. Also some buildings or assets were proposed to Preservation Boards to be registered. Furthermore, 74 types of data including location, architectural description, conservation state, materials, problems and bibliography were recorded. Database allows printing 4 types of inventory forms representing current state of the value. Database was integrated with spatial data to produce analytical maps. Database created by the project has been shared via internet and books to lead other projects about cultural heritage.
\end{abstract}

\section{INTRODUCTION}

\subsection{General Aim}

Documentation is the first essential condition of architectural restoration and conservation projects. Decision process about these projects elementarily depends on such documentation results. At the beginning of every kind of projects related to architectural restoration or site conservation, it is necessary to reach the accurate, scientific and current information about the cultural assets. Istanbul has a wide range of cultural assets which belong to different eras or even empires. The history of the city means almost 10.500 years, according to recent archaeological excavations. One of the most important urgent needs is 'to reach the updated data' about the conservation state of Istanbul.

According to the existing data which belongs to 2015 and produced by the Ministry of Culture and Tourism of Turkey, the number of cultural assets of Istanbul had been declared as 30.694. Also Directorate of Urban Planning of Istanbul Metropolitan Municipality had studied about the cultural assets in 2009 and results had shown that there had been 31.769 assets throughout the city. Disparity among the results of different establishments proves the necessity of common numeric databank.

\begin{tabular}{|l|c|}
\hline Reference & Number of Asssets \\
\hline Ministry of Culture and Tourism & 30.694 \\
Directorate of Urban Planning (IMM) & 31.769 \\
\hline
\end{tabular}

Table 1. Number of Cultural Asssets in Istanbul

\subsection{Description}

Digitization of cultural heritage is one of the most effective methods for leading and encouraging various architectural conservation projects. An accurate methodology for collecting and processing the entire data of cultural assets was urgently required in especially highly deteriorated heritage areas, in order to examine both the loss of authenticity and the ratio of transformation. Being one of the most important cities of Turkey in terms of archaeological, monumental, civil, modern and also industrial heritage, Istanbul reflects the range of architectural characteristics of the country.

One of the most important urgent needs is 'to reach the updated data about the conservation state of World Heritage Sites'. Historic areas of Istanbul were registered in the World Heritage List in 1985. In the mentioned list, Istanbul was represented by four areas with outstanding universal value:

1. Sultanahmet Archaeological Park

2. Land Walls of Istanbul

3. Süleymaniye Mosque and its associated conservation area

4. Zeyrek Mosque (Pantocrator Church) and its associated conservation area. In order to follow the conservation state of these areas, the Site Managements Directorate of Istanbul needs information and statistics periodically. Historical Peninsula including these listed areas has $31 \%$ of the registered historic values throughout Istanbul. Sultanahmet Archaeological Park which is the heart of the old city includes the remains of Istanbul's cultural and archaeological heritage, of Byzantion, Roman and Ottoman settlements such as Hippodrome, Hagia Sophia and Topkapi Palace. The Theodosian Land Walls which have a length of $5,7 \mathrm{~km}$ starts from the Golden Horn at north 
and ends to Yedikule at south. Süleymaniye and Zeyrek are the typical quarters representing the old settlement manner, timber houses with narrow streets. During centuries, especially civil architecture of Istanbul has been damaged because of fires, earthquakes or other drastic changes. Istanbul represents ancient periods, Hellenistic era, East Roman, Byzantine and Ottoman empires and also architecture of 20th century, so the cultural heritage of Istanbul requires utmost care for any kind of conservation studies or research projects.

As a result of the immensity of this scale and high density of the city, complexity and conflict might be occurred among the governmental and non-governmental heritage institutions. On request for the development and presentation of new heritage management policies for the historical areas of Istanbul, a basic inventory and documentation project was initiated at Istanbul Metropolitan Municipality in 2015.

\subsection{Content}

Scientific documentation of the cultural heritage is the main issue for conservation. In spite of the fact that there have been plenty of associations and institutions in Turkey working in this field, lack of an exclusive databank of registered cultural properties was the major concern. For this reason, it was decided to undertake the responsibility of creating a whole databank for the historical and cultural assets in Istanbul by the local authority.

This is 'the first and the most comprehensive inventory project' created throughout Istanbul, which is directly focused on the cultural heritage of the whole city and led by the local government by means of a holistic approach. Directorate of Cultural Heritage Preservation (CHP) assumed the responsibility of creating the database in detail, providing its accessibility through web and presenting the current data by books. It was also aimed to provide accurate information and multimedia, not only for existing but also further projects in respect of cultural heritage and preservation. An interdisciplinary scientific approach was developed and implemented. The project aimed to create an integrated database of Istanbul's cultural heritage, provide rapid accessibility through web and share all via the publications.

\section{PROJECT METHODOLOGY}

\subsection{Time Schedule}

Inventory Project was planned to be completed in four phases up to 2019. At the beginning of the project, it was known that 31.769 cultural assets existed in Istanbul according to the data produced in 2009. After the research and data acquisition work made in the preparation phase, it was clear that the estimated number of cultural assets in Istanbul would reach to 35.000 approximately.

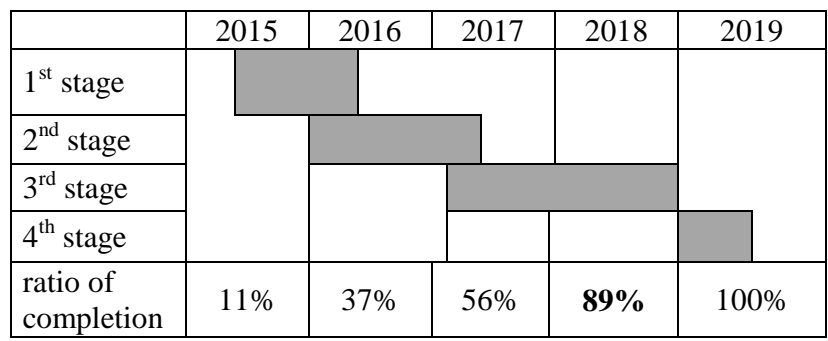

Table 2. Time Schedule of the Inventory Project
Directorate of CHP had started the Inventory Project in 2015 and $90 \%$ of the whole project is completed by March 2019. The project will be completed by this year.

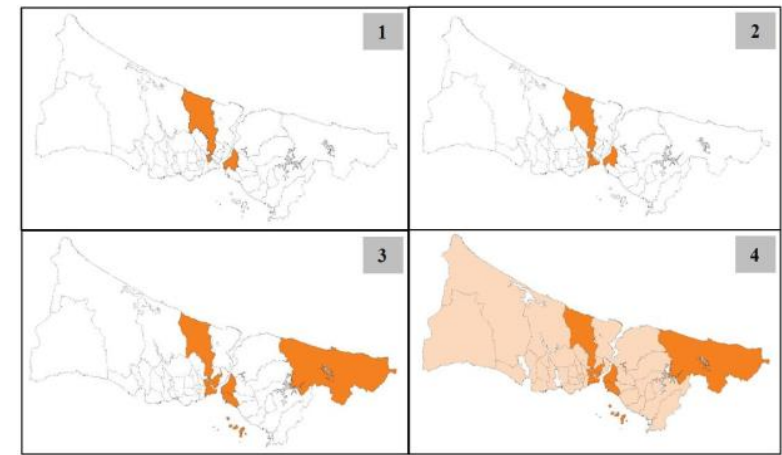

Figure 1. Map of Istanbul - Steps of the Project (2015-2019)

According to the research, it was defined that Historical Peninsula (Fatih district) included $31 \%$ of all registered cultural assets of Istanbul, whereas Beyoglu district (in the European side) had $18 \%$ and Uskudar district (in the Asian side) followed them by $8 \%$. These numbers were considered while the working plan was created. At the first stage of the project, Uskudar and Eyup districts were studied with limited number of experts in order to gain experience and build a system for further stages. Historical Peninsula (Fatih district), which is the most important area in terms of cultural heritage, was studied at the second stage and the project team took the advantage of previous experiences. Each district had required a different working plan which was adapted to the specific conditions and problems of the area.

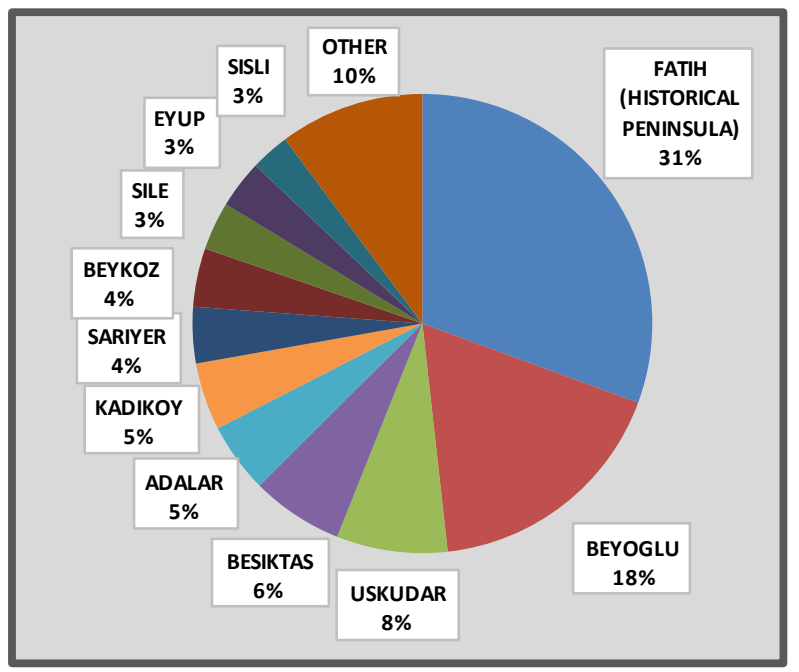

Figure 2. Distribution of Cultural Asssets in Districts - Istanbul

\subsection{Methodology}

While the methodology was created, eight principal issues were considered: Integrated Approach, Expertise, Multi-disciplinary Team, Cooperation, Numerical Analysis, Classification of Data, Digital Archive, Continuity. Regarding these principles, project methodology was determined to be implemented in six steps:

1- Preparation and Education

2- Research and Data Collection

3- Field Work-Documentation and Photography

4- Data Entry-Inventory Forms

5- Analytical Study and Reporting

6- Presentation and Publication 
Preparation and Education: Considering the importance of a multi-disciplinary team, an education programme for two weeks was organised and implemented. The aim, method and description of the inventory project were defined and discussed during the education programme. Prof. Dr. Zeynep Ahunbay gave lectures about the background, importance and examples of the previous inventory studies and mentioned some important architectural references to be used during the researches. Prof. Dr. Ozer Kanburoglu gave advices about architectural photography and made practices with the project team on site. Dr. Esra Kudde was the instructor for the project and informed the project team about architectural descriptions and classification methods.

Research and Data Collection: Before starting the field work, it was planned to gather information from different institutions and establishments in order to evaluate the quality and accuracy of the existing data. During the Inventory Project, a huge amount of data including old maps (Goad, Pervititch, Ayverdi, Moltke, etc.), old photographs, archive documents (decisions of Preservation Boards and Encumen Archives), drawings and projects were brought together and classified according to their type and content. The most important part of the digital resources included the decision reports of the previous meetings of the Preservation Boards starting from 1950s. Over 900.000 files of the Archives of Preservation Boards were classified and over 100.000 old photographs were identified. Literature research was also made at this step.

Field Work-Documentation and Photography: After the preparation of documents and maps, each registered historical value including monuments, civil architectural or urban elements was visited on-site, observed and photographed. Each group constituted for the site work included an architect, an urban planner and an art historian or an archaeologist. The existing state of the value was documented following the instructions and all of the cultural assets were photographed. Also some buildings or urban elements were documented to be proposed to the Preservation Boards for the registration.

Data Entry-Inventory Forms: Numeric, textual and spatial data were recorded by using the special software which was developed for this inventory project. By using the software, 74 types of data including several features of the cultural assets such as location, physical information, architectural description, conservation state, materials, construction technique, problems, bibliography, etc. were recorded in detail. Software was also developed synchronously by data acquisition. This was one of the best opportunities in order to realize and solve the handicaps of data processing such as types of inquiries, printing formats, GIS tools, multiselection or editing options. The software is written to be used and redeveloped after five years' time to be updated. The existing version of the software allows printing 4 types of inventory forms which represent the current state of the value. One of these forms in A3 size is the general accepted form by the European Council and mostly used in official procedures. The second form in A3 size is generated by our Project Team and includes all of the numeric data recorded in the software with two photographs and a site plan. Many types of combination for filtering is available. The third form in square $(30 * 30 \mathrm{~cm})$ is also created by our team to be used in the publications. The last form is also designed for publications and contains at least one old photograph or historical map of the mentioned asset. This gives way to present and describe some cultural values, especially the missing ones, by using a more explanatory way.

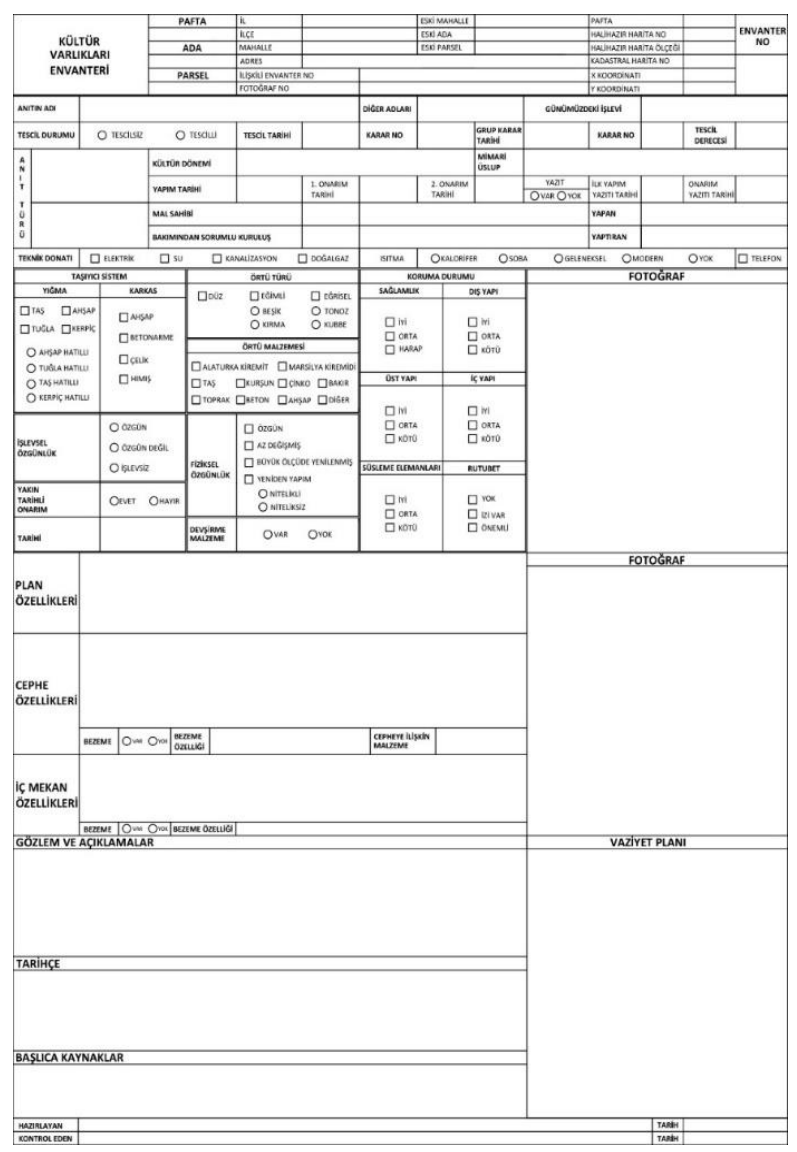

Figure 3. Inventory Form Designed by the Project Team (2016)

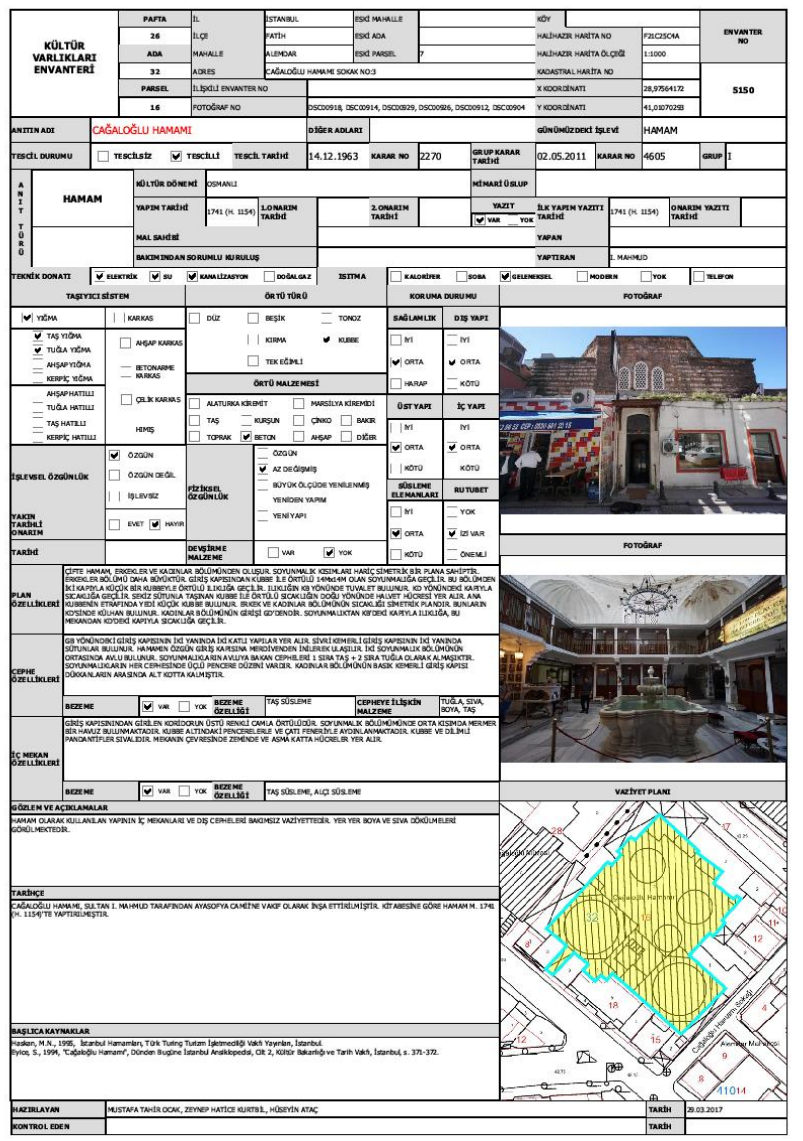

Figure 4. An Example of Inventory Form Including 74 Types of Inquirable Data Designed by the Project Team (2016) 
Analytical Study and Reporting: The analytical studies are planned according to follow the standard guidelines of architectural and urban heritage conservation principles. The variety of monument types, functions, structural strength, state of conservation, distribution of ownership and many other subjects were analysed and visualized. This gives an opportunity to the researchers for further projects. Urban planners benefit from recent maps and create the most accurate spatial data together with the architects. The software which was based on GIS gives way to create, edit and process the data.

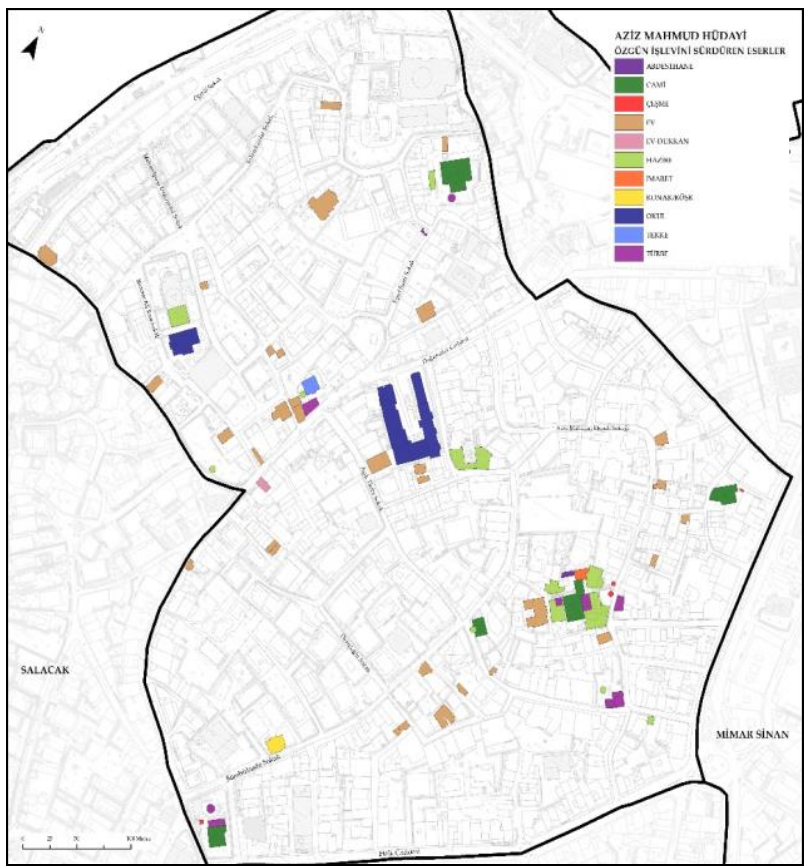

Figure 5. Example of Analytical Maps - 'Functional Originality'

Presentation and Publication: When data processing is completed, the databank will be open to the users via the official website. Analytical reports, booklets and publications are being prepared for sharing the information among the network. The cultural values of Istanbul will be published in a set of 45 volumes including the inventory forms. Also, 15 volumes of analytical books for specific districts will be prepared including the evaluation of the preservation state of Istanbul. It is planned to update the databank after five years and continue the process periodically.

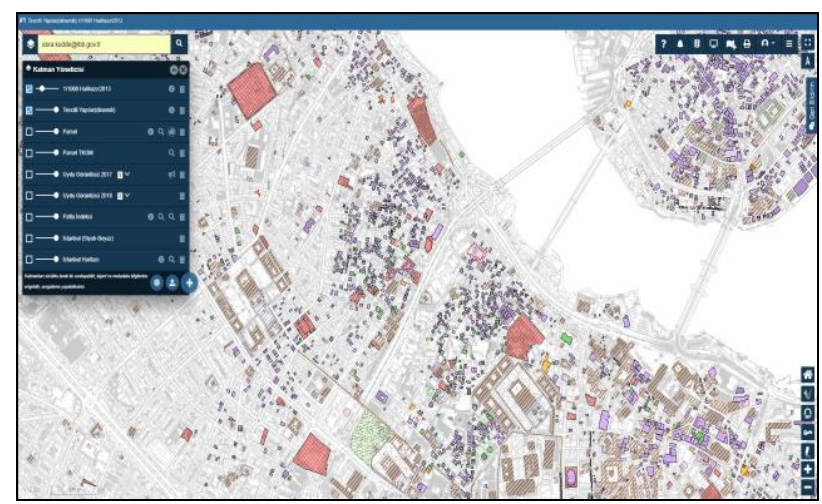

Figure 6. Presentation of the Databank via the Internet (https://cbs.ibb.gov.tr)

\subsection{Results}

After the project is finished completely, there will be 45 series of inventory books including all of the cultural assets of Istanbul. Also, analytical studies and evaluations about the architectural conservation state of each district of Istanbul will be published and delivered. The classification methodology and the data processing system will be useful for future projects. The software will be continued to be redeveloped until it responds well to the possible scenarios of inquiry. It is aimed to serve an updated cultural database of Istanbul to whom has duty in architectural conservation field and/or plans to make research, conservation projects, risk assessment, disaster management, thematic mapping, monitoring projects or many other studies. The method and results of this documentation work will be presented in this paper, to be used as a model for creating new projects and to be criticised in terms of several heritage and risk management issues.

\begin{tabular}{|l|l|l|l|l|}
\hline STAGE & $\begin{array}{l}\text { NAME OF } \\
\text { DISTRICTS }\end{array}$ & DATE & $\begin{array}{l}\text { NUMBER OF } \\
\text { ASSETS } \\
\text { (EXPECD) }\end{array}$ & $\begin{array}{l}\text { NUMBER OF } \\
\text { ASSETS } \\
\text { (ACTUL) }\end{array}$ \\
\hline & 2018
\end{tabular}

Table 3. Results of the Inventory Project, Distribution of Cultural Assets According to Districts of Istanbul (2015-2019) 


\section{CONCLUSION}

Conservation is a wide and multidisciplinary field where science and culture come together. At the beginning of many conservation studies, a reliable, accurate and numeric data about the working space is demanded. The final database including all of the information, archive and results of the Inventory Work will be a very useful and comprehensive reference for conservation projects. Our department assumed this important responsibility for Istanbul. Classifying the various types of visual data and creating a satisfying methodology for updating the database were the keystones of the whole project. This project will be continued in further years and the historical database of Istanbul will be updated periodically. Istanbul may provide a good model for other cities especially including the World Heritage Areas through the world.

\section{REFERENCES}

Ahunbay, Z. 2009. Cultural Heritage of Turkey. Ministry of Culture and Tourism. Ankara: p. 128-132.

Gülersoy, N.Z. \& Tezer, A. Yiğiter, R.G. Koramaz, K. Günay, Z. 2008. Istanbul Project: Istanbul Historic Peninsula Conservation Study Vol 2, ITU: 6-10.

İstanbul. 2011. İstanbul Tarihi Yarımada Yönetim Planı (The Management Plan for the Historical Peninsula of Istanbul): 1521.

Kudde, E. (ed.). 2018. İstanbul Envanteri - Üsküdar, İstanbul Büyükşsehir Belediyesi Kültürel Miras Koruma Müdürlügü: İstanbul.

URL 1. Ministry of Culture and Tourism, viewed 15 April 2018, from http://www.kulturvarliklari.gov.tr/TR,44423/dunyamiras-listesi.html.

URL 2. Ministry of Culture and Tourism, viewed 20 April 2018, http://www.kulturvarliklari.gov.tr/TR,44799/illere-gorekorunmasi-gerekli-tasinmaz-kultur-varligi-i-.html 